\title{
ESTUDO DAS PROPRIEDADES DO BIOSSURFACTANTE FORMULADO PRODUZIDO POR CANDIDA BOMBICOLA UTILIZANDO RESIDUOS DE BAIXO CUSTO
}

\author{
B. G. FREITAS ${ }^{1}$, N.M.P.ROCHA E SILVA ${ }^{1,2}$, J.M. LUNA $^{1,2}$, R.D. RUFINO ${ }^{1,2}$, L.A. \\ SARUBBO $^{1,2}$
}

\author{
${ }^{1}$ CCT - Universidade Católica de Pernambuco \\ ${ }^{2}$ CGTI - Centro de Gestão de Tecnologia e Inovação \\ E-mail para contato:galdino1039@hotmail.com
}

\begin{abstract}
RESUMO - Os biossurfactantes se destacam como tecnologia alternativa no controle da poluição provocada por hidrocarbonetos. Neste sentido a Candida bombicola foi cultivada em meio contendo $5 \%$ de melaço, $5 \%$ de óleo de fritura e $5 \%$ de milhocina, durante 120 horas a $200 \mathrm{rpm}$ para a produção de biossurfactante. O liquido metabólico livre de células contendo o biossurfactante foi submetido a um conservante comercial a fim de testar sua estabilidade frente a diferentes variações de $\mathrm{pH}$, temperatura e sal. Após formulação do líquido metabólico, foram estocadas à $28^{\circ} \mathrm{C}$ por 120 dias, onde foram realizados testes de tensão superficial, atividade de emulsificação e capacidade de dispersão. Os resultados obtidos demonstraram estabilidade na tensão superficial frente às variações de $\mathrm{pH}$, temperatura e salinidade. Os melhores percentuais do índice de emulsificação foram para o óleo de motor e óleo de milho. Os resultados obtidos foram promissores para utilização no controle da poluição ambiental.
\end{abstract}

\section{INTRDUÇÃO}

O petróleo é uma mistura complexa de compostos não aquosos e hidrofóbicos utilizado desde 5000 anos a.C. O auge de sua exploração iniciou-se por volta de 1930, principalmente como matriz energética, com o surgimento de motores a explosão. A partir daí a indústria petroleira ascendeu de forma expressiva. No entanto, este grande aumento na utilização de hidrocarbonetos como combustível e todas as etapas envolvidas no transporte, estocagem e distribuição do óleo cru e de seus derivados envolve grandes riscos de derrames acidentais, os quais têm sido um dos principais problemas ambientais, além de social e econômico, nas últimas décadas. Tem-se, como exemplo, o caso da maré negra que se espalhou no Golfo do México desde a explosão e afundamento da plataforma da British Petroleum (Oliveira; Silveira, 2010). 
A biorremediação utiliza o metabolismo de micro-organismos para eliminação de poluentes no ambiente ou a sua redução a níveis de concentração aceitáveis. Este processo pode ser acelerado pela a ação de agentes surfactantes microbianos, os biossurfactantes, os quais são compostos tensoativos produzidos por bactérias, leveduras e alguns fungos filamentosos. (Weber; Santos, 2013).

Portanto, os biossurfactantes são moléculas anfipáticas contendo porções hidrofílicas e hidrofóbicas que se particionam, preferencialmente na interface entre fases fluidas que possuem diferentes graus de polaridade e pontes de hidrogênio, como interfaces óleo/água ou ar/água, permitindo também a redução da tensão superficial e consequentemente o maior acesso dos micro-organismos degradadores às gotas emulsificadas (Cruz, 2012; Fracchia, et al., 2012).

Os biossurfactantes apresentam, ainda, inúmeras vantagens sobre os surfactantes de origem química, tais como estabilidade frente a ampla faixa de $\mathrm{pH}$ e temperaturas elevadas, bem como resistência a altas concentrações salinas (Marchant; Banat, 2012b)

A maioria dos biossurfactantes conhecidos é produzida em substratos insolúveis em água como hidrocarbonetos sólidos e líquidos, óleos e gorduras, embora muitos tenham sido obtidos a partir de substratos solúveis (Pacwa-plociniczak et al., 2011). A disponibilidade e o tipo de matéria-prima podem contribuir consideravelmente para o custo de produção. Estimase que $10 \%$ a $30 \%$ da matéria-prima represente o custo total de um produto biotecnológico (Mukherjee et al., 2006). Por outro lado, milhões de resíduos poluentes são jogados a cada ano no mundo. $\mathrm{O}$ tratamento e a remoção destes resíduos também representam um alto custo para várias indústrias (Marchant; Banat, 2012).

Nesse sentido, os resíduos industriais têm despertado grande interesse dos pesquisadores como substratos de baixo custo para a produção de biossurfactantes, tais como os resíduos de fritura de óleos vegetais, resíduos de destilaria de óleos, resíduos da indústria de laticínios (soro de leite), melaço de cana e glicerina têm sido citados na literatura (Gallert; Winter, 2002; Luna et al., 2013).

Contudo, o objetivo desse trabalho foi testar a estabilidade do biossurfactante produzido pela levedura Candida bombicola cultivada em resíduos industriais como substratos, com vistas à aplicação dessa biomolécula como aditivo comerciai coadjuvante dos processos de remediação de poluentes hidrofóbicos gerados na indústria de petróleo, especialmente por indústrias que invistam no desenvolvimento de um biorremediador com aplicação em uma eventual biorremediação.

\section{MATERIAL E MÉTODOS}

\subsection{Micro-organismo}


A levedura Candida bombicola, mantida em meio YMA (Yeast Mold Ágar) foi utilizada como micro-organismo produtor do biossurfactante. Repiques foram mensalmente realizados para manter a viabilidade celular.

\subsection{Meios de manutenção e crescimento do inóculo}

A manutenção da levedura foi realizada utilizando-se o meio Yeast Mold Ágar (YMA), com a seguinte composição: extrato de levedura $(0,3 \%)$, D-glicose $(1 \%)$, peptona $(0,5 \%)$, ágar $(2 \%)$ Água destilada q.s.p $(100 \mathrm{~mL})$. Os componentes foram solubilizados e esterilizados em autoclave a $121^{\circ} \mathrm{C}$ por 20 minutos. Quando excluído o ágar, constituiu o meio de crescimento, Yeast Mold Broth (YMB).

\subsection{Substratos do meio de produção}

As fermentações para produção do biossurfactante foram realizadas em meio formulado com água destilada contendo milhocina, melaço cana e óleo de fritura (residual) ambos a 5\%.Após o preparo dos meios, o pH foi ajustado para 6,0 com o auxílio de uma solução $5 \mathrm{M}$ de $\mathrm{NaOH}$ e estes foram autoclavados a $121^{\circ} \mathrm{C}$ por 20 minutos.

\subsection{Preparação e crescimento do inóculo}

O inóculo foi padronizado transferindo-se as culturas para um tubo contendo o meio YMA, a fim de se obter uma cultura jovem. Em seguida, a amostra foi transferida para frascos contendo $50 \mathrm{~mL}$ do meio YMB e incubados sob agitação de $200 \mathrm{rpm}$ a $27^{\circ} \mathrm{C}$ durante 24 horas. Após este período, foram realizadas diluições até se obter a concentração final de células desejadas de $5 \%(\mathrm{v} / \mathrm{v})$.

\subsection{Produção do biossurfactante}

As fermentações para a produção do biossurfactante foram realizadas em frascos de Erlenmeyer com $1000 \mathrm{~mL}$ de capacidade contendo $500 \mathrm{~mL}$ do meio de produção e incubados com a suspensão celular de 5\% (v/v). Os frascos foram mantidos sob agitação orbital 180 rpm, durante 120 horas, à temperatura de $30^{\circ} \mathrm{C}$.

\subsection{Estabilização do líquido metabólico com propriedade surfactante}

O líquido metabólico livre de células contendo o biossurfactante produzido foi conservado adicionado sorbato de potássio (2\%), o qual foi estocado à temperatura ambiente ao longo de 90 dias para a observação da estabilidade. Teste foram realizados para determinação do tempo de estocagem $(0,15,30,45,90$ e 120 dias), verificando-se a tensão superficial, capacidade de emulsificação e dispersão de compostos hidrofóbicos nas diferentescondições de $\mathrm{pH}(5,7,9)$, $\mathrm{NaCl}(1,3,5 \%)$ e aquecimento a 40 e $50^{\circ} \mathrm{C}$ conforme descrito abaixo.Todas as análises foram realizadas em triplicata. 


\subsection{Determinação da tensão superficial}

A tensão superficial foi medida no líquido metabólico livre de células em tensiômetro KSV Sigma 70 (Finland) utilizando-se o anel NUOY, pela imersão do anel de platina no líquido e registrando-se a força requerida para puxá-lo através da interface ar-liquido.

\subsection{Determinação da atividade de emulsificação}

Para determinar as atividades de emulsificação, as amostras do liquido metabólico livre de células foram analisadas segundo a metodologia descrita por Cooper Goldenberg (1987).

\subsection{Experimento de dispersão de composto hidrofóbico em água do mar}

A capacidade de dispersão foi simulada em laboratório contaminando-se amostras de água do mar com óleo de motor. Os testes foram conduzidos pela adição do líquido metabólico livre de células da solução do biossurfactante (1:2, 1:8 e 1:25, vol/vol) do óleo de motor. Posteriormente mediu-se o halo formado pela dispersão do biossurfactante no óleo.

\section{RESULTADOS E DISCUSSÃO}

\subsection{Avaliação da estabilidade do biossurfactante produzido por Candida bombicola}

O líquido metabólico (Figura 1) apresentou tensão superficial praticamente estável no Controle. Foi observado que nos pH 7 e 9 o líquido metabólico apresentou uma pequena variação na tensão superficial. Com relação à variação da concentração de $\mathrm{NaCl}$ foi observado um aumento na tensão superficial no quadragésimo e nonagésimo dia de experimento. Já para a variação da temperatura o liquido metabólico não apresentou alterações significativas na tensão superficial. 


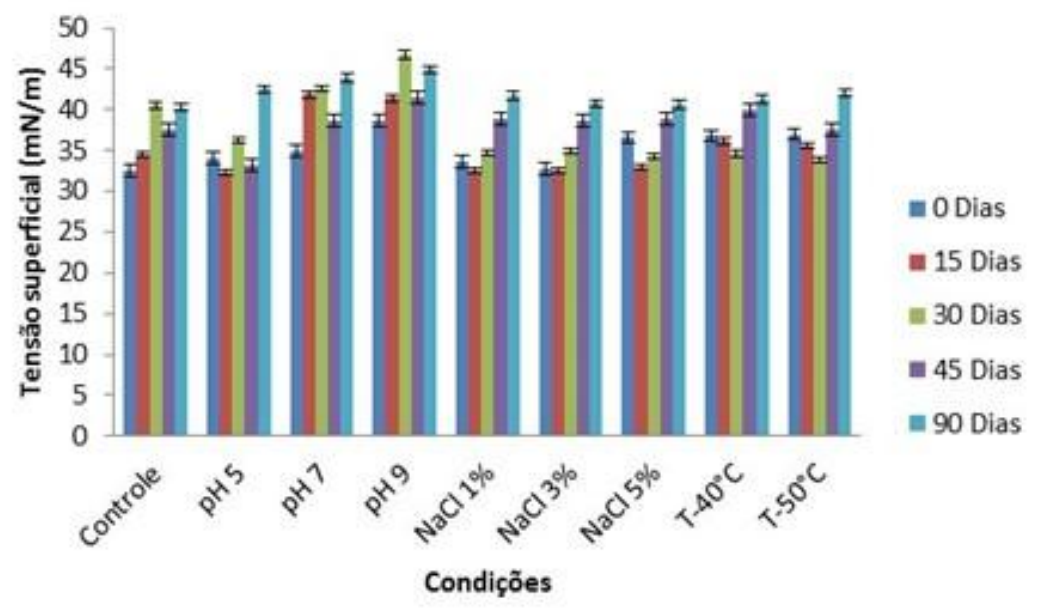

Figura 1 - Tensões superficiais do biossurfactante sob conservação com adição de sorbato de potássio a $0,2 \%$ durante 90 dias quando submetido à variação de $\mathrm{pH}$, adição de $\mathrm{NaCl} \mathrm{e}$ temperatura.

Os testes para determinação do índice de emulsificação (Figura 2 A) mostram que quando o biossurfactantefoi submetido à variação de $\mathrm{pH}$, houve uma redução no índice durante o décimo quinto dia, posteriormente não se observou alterações significativas.

Para as concentrações de $\mathrm{NaCl}$, biossurfactante apresentou o melhor percentual de emulsificação (60\%) quando adicionado $1 \%$ do salno quadragésimo dia de experimento. Já no décimo quinto dia foi observado uma redução no índice independente das concentrações testada, enquanto que no trigésimo e nonagésimo dia de experimento as emulsões mantiveram-se constantes comparada-as ao controle.

Já às variações de temperaturas, observou-se que houve uma diminuição de índice no décimo quinto dia, quando comparado ao controle no qual foram observados valores de $40 \%$.

Na Figura 2 B, quando o biossurfactante foi submetido à variação de $\mathrm{pH}$, o índice permaneceu praticamente estável, enquanto que no quadragésimo dia foi observado um aumento na emulsão de $65 \%$ para o $\mathrm{pH} 9$.

Com relação à variação da concentração de $\mathrm{NaCl}$, foi observado que os maiores resultados do índice de emulsificação foi obtido no trigésimo dia de experimento.

No aquecimento, houve uma diminuição no índice de emulsificação à temperatura de 40 ${ }^{\circ} \mathrm{C}$ no décimo quinto e quadragésimo dia,comparando-os ao controle. Os melhores percentuais foram obtidos no trigésimo dia.

Em (Figura $2 \mathrm{C}$ ), quando o biossurfactante foi submetido à variação de $\mathrm{pH}$, houve um aumento no índice de $75 \%$ para pH 7 no trigésimo dia de experimento. Para as variações das concentrações de $\mathrm{NaCl}$, o biossurfactante apresentou as melhores emulsõesno quadragésimo e 
nonagésimo dia de experimento. Com relação à variação da temperatura, foi observado que a $50{ }^{\circ} \mathrm{C}$ ocorreu um aumentou no índice.

A

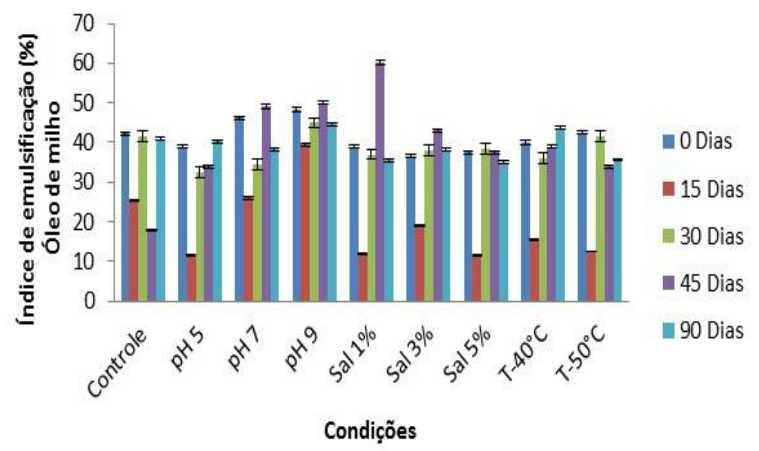

B

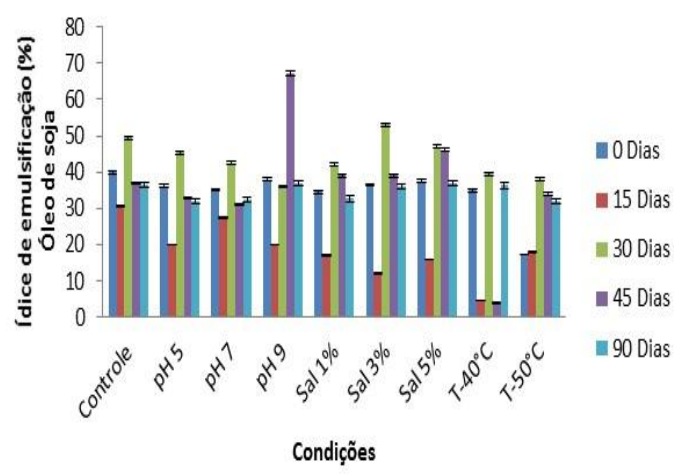

$c$

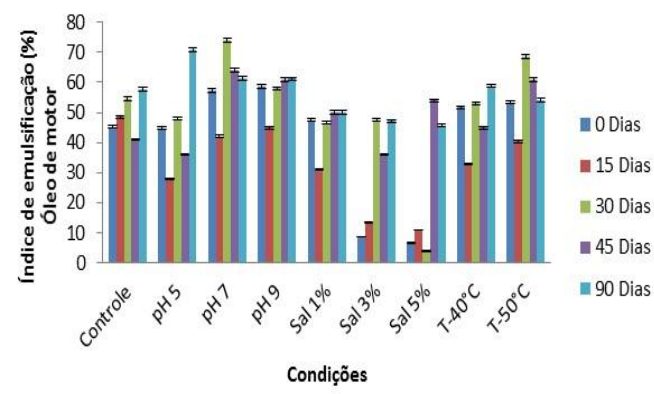

Figura 2 - Índice de emulsificação do biossurfactante produzido contendo sorbato de potássio a 0,2\% utilizando óleos de milho (A), soja (B) e motor (C), variando: $\mathrm{pH}, \mathrm{NaCl}$ e temperatura.

Na Figura 3 A, foi possível observar que a variação do $\mathrm{pH}$ alterou o desempenho do líquido metabólico em relação aos índices de dispersão alcançados quando comparados ao controle.Em relação aos testes com variação de $\mathrm{NaCl}$, os resultados demonstraram um redução no índice de dispersão, o qual permaneceu praticamente estável frente a adição de sal.Com relação à variação da temperatura, os melhores resultados do índice de dispersão foram obtidos quando houve exposição do biossurfactante à temperatura de $50^{\circ} \mathrm{C}$.

Na Figura 3 B pode-se observar que o biossurfactante testado apresentou uma redução na sua atividade dispersante quando comparado com o controle em todas as variações testadas. 
Observou-se que houve uma redução na atividade dispersante do liquido metabolico contendo $0,2 \%$ de sorbato de potássio quando submetido as variações de $\mathrm{pH}$, concentração de $\mathrm{NaCl}$ e temperatura (Figuras $3 \mathrm{C}$ ).
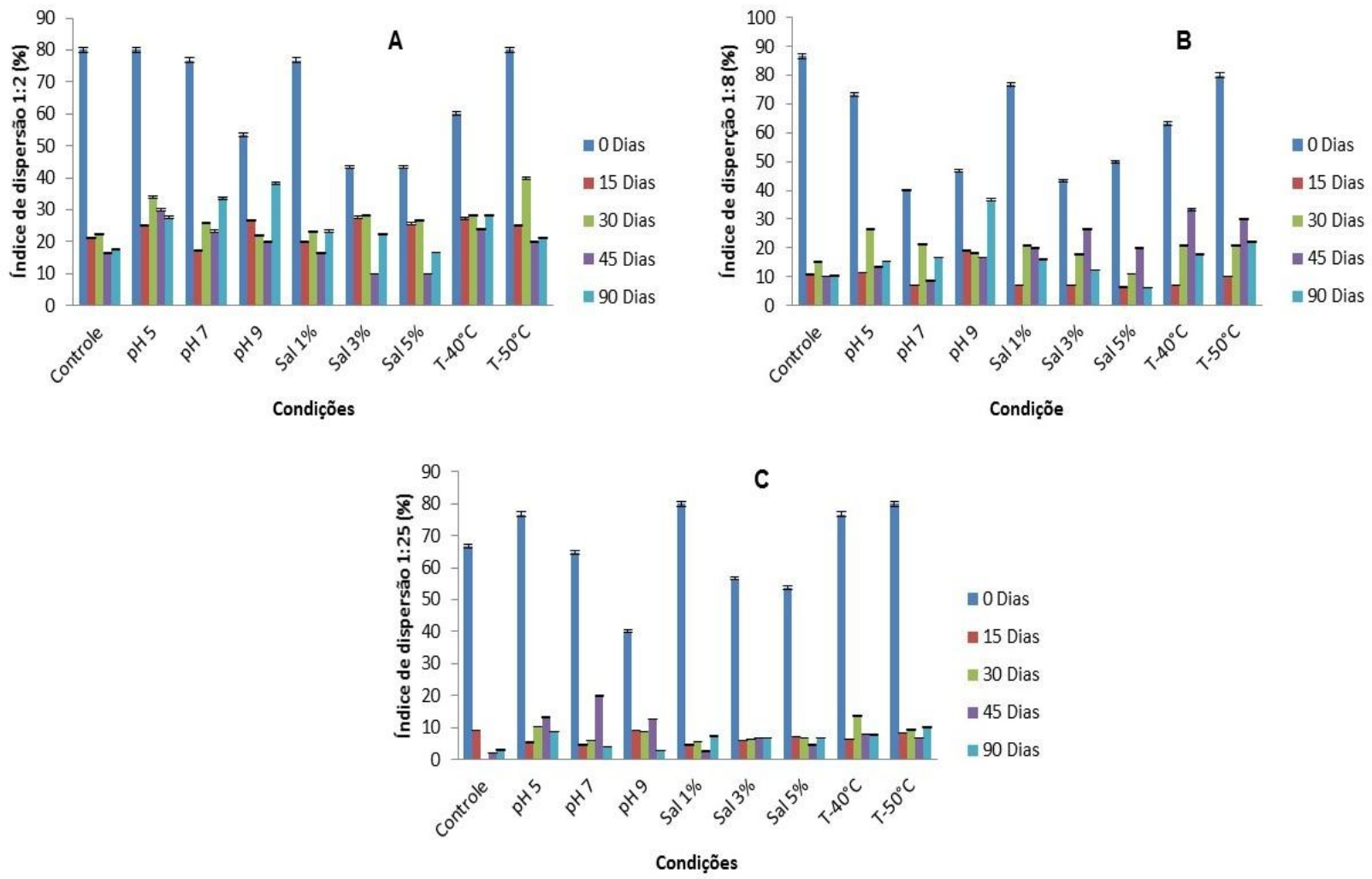

Figura 3 - Índice de dispersão do biossurfactante utilizando de óleo motor nas proporções de 1:2 (A), 1:8 (B) e 1:25(C) em relação às condições de $\mathrm{pH}, \mathrm{NaCl}$ e temperatura.

\section{CONCLUSÃO}

O biossurfactante produzido por Candida bombicola apresentou excelente resultado com relação ao método de formulação testado, podendo ser considerado um produto promissor para utilização no controle da poluição ambiental causada por petróleo e derivados no meio ambiente terrestre e aquático.

\section{REFERÊNCIAS}


COOPER, D.G., GOLDENBERG, B.G. Surface active agents from two Bacillus species. Appl. Enviromen. Microbiol. v.53, p.224-229, 1987.

CRUZ, J. F.;Avaliação da eficiência de surfactantes no processo de biodegradação de petróleo bruto em simulações de derrames no mar. Dissertação apresentada ao Programa de PósGraduação em Geoquímica: Petróleo e Meio Ambiente - POSPETRO, Instituto de Geociências, Universidade Federal da Bahia, Bahia,p. 78, 2012.

DELEU, M.; PAQUOT, M. From renewable vegetables resources to microorganisms: new trends in surfactants. Computers Rendus Chimie., v. 7, p. 641-646, 2004.

FRACCHIA, L.; CAVALLO, M.; MARTINOTTI,G.M., BANAT, I.M. Biosurfactants and bioemuisifiers related applications - Present Status and Future Potentials, Biomedical Science, Engineering and Technology, Dhanjoo N. Ghista (Ed.), p.325-370, 2012.

GALLERT, C. WINTER, J. Solid and liquid residues as raw materials for biotechnology. Naturwissenschaften., v. 89, p. 483-496, 2002.

LUNA, J. M., RUFINO, R. D., SARUBBO, L. A., CAMPOS-TAKAKI, G. M., Characterization, surface properties and biological activity of a biosurfactant produced from industrial waste by Candida sphaerica UCP0995 for application in the petroleum industry. Colloids surf B., p. 36, 2013.

MARCHANT, R.; BANAT, I.M. Biosurfactants: a sustainable replacement for chemical surfactants.Biotechnology Letters., v. 34, p. 1597-1605, 2012a.

MARCHANT, R.; BANAT, I.M. Microbial biosurfactants: challenges and opportunities for future exploitation. Trends in Biotechnology., v. 11, p. 558-565, $2012 \mathrm{~b}$.

MUKHERJEE, S.; DAS, P.; SEN, R. Towards commercial production of microbial surfactants. Trends in Biotechnology., v. 24, p. 509-515, 2006.

OLIVEIRA, M. S.; SILVEIRA, E.Entre esponjas e detergentes: novos produtos podem remover petróleo derramado no mar. Revista Pesquisa FAPESP. Edição 176 - Outubro de 2010.

PACWA-PLOCINICZAK, M.; PLAZA, G.A.; PIOTROWSKA-SEGET, Z.; CAMEOTRA, S.S. Environmental Applications of Biosurfactants: Recent Advances. Intern. J. Mol. Science.,v. 13, 633-654, 2011.

WEBER, B. D.; SANTOS, A. A., Utilização da biorremediação como ferramenta para o controle da degradação ambiental causada pelo petróleo e seus derivados, Engenharia Ambiental Espírito Santo do Pinhal, v. 10, n. 1, p. 114-133, jan. / fev. 2013. 